\title{
La justicia transicional en Colombia: ¿Un instrumento creado para erradicar la impunidad?
}

\author{
Transitional Justice in Colombia: A Mechanism to \\ Erradicate Impunity?
}
A Justiça Transicional na Colômbia: Um Instrumento Criado para Erradicar a Impunidade?

Joana Loyo Cabezudo**

Fecha de recepción: 28 de junio de 2016
Fecha de aprobación: 15 de noviembre de 2016
Doi: http://dx.doi.org/10.12804/revistas.urosario.edu.co/anidip/a.5669

Para citar este artículo: Loyo Cabezudo, J. (2017). La Justicia Transicional En Colombia: ¿Un Instrumento Creado Para Erradicar La Impunidad? Anuario Iberoamericano de Derecho Internacional Penal-ANIDIP ANIDIP, 5, 32-61. Doi: http://dx.doi.org//10.12804/revistas.urosario.edu. co/anidip/a.5669

\section{Resumen}

El Acuerdo Final de 12 de noviembre de 2016 entre el Gobierno de Colombia y las FARC-EP para poner fin al conflicto plantea, en la parte relativa al Acuerdo sobre Víctimas, complejos debates en torno a su adecuación a los estándares internacionales previstos, especialmente al Estatuto de Roma de la Corte Penal Internacional. El presente ensayo aborda la cuestión relativa a si el Acuerdo es un instrumento dirigido o no a erradicar la impunidad. Para ello analiza desde el punto de vista del Derecho internacional qué implica la impunidad, la relación que ésta mantiene con la justicia transicional y la influencia que la Corte Penal Internacional ejerce en estos procesos transicionales.

Palabras clave: Justicia transicional, Corte Penal Internacional, impunidad, sanción, Colombia.

Artículo realizado durante el período de disfrute de la beca del Programa Predoctoral de Formación de Personal Investiģador No Doctor, financiada por el Departamento de Educación, Política Lingüística y Cultura del Gobierno Vasco (PRE-2015, MOD.A).

** Doctoranda en el área de Derecho Internacional Público de la Facultad de Derecho de la Universidad del País Vasco (UPV/EHU). La autora quiere mostrar su más sincero agradecimiento a la Doctora María Dolores Bollo Arocena por la supervisión de la investiģación. Correo electrónico: joana.loyo@ehu.eus 


\section{Abstract}

The 12 November 2016 Final Agreement between the Colombian government and the FARC-EP to put an end to the armed conflict in Colombia, raises a number of issues on whether various aspects of the Agreement on Victims meet international legal standards, especially those provided for in the Statute of the International Criminal Court. The present article looks into the issue of whether or not the Final Agreement is an instrument to eradicate impunity. In order to do so, the article analyses what impunity from an international law perspective is, the relationship between impunity and transitional justice and the influence of the International Criminal Court in transitional processes.

Keywords: Transitional Justice, International Criminal Court, impunity, sanction, Colombia.

\section{Resumo}

O Acordo Final do 12 de novembro de 2016 entre o Governo da Colômbia e as FARC-EP para pôr fim ao conflito apresenta na parte relativa ao Acordo sobre Vítimas complexos debates em torno à sua adequação aos standards internacionais previstos, especialmente ao Estatuto de Roma da Corte Penal Internacional que implica a impunidade, a relação que esta mantém com a justiça transicional e a influência que a Corte Penal Internacional exerce nestes processos transicionais.

Palavras-chave: Justiça transicional, Corte Penal Internacional, Impunidade,

Sanção, Colômbia

\section{Introducción}

El día 24 de agosto de 2016, el Gobierno colombiano y las FARC-EP anunciaron que, tras más de cuatro año de negociaciones, ${ }^{1}$ habían suscrito un Acuerdo Final para la Terminación del Conflicto y la Construcción de una Paz Estable y Duradera. No obstante, en el plebiscito convocado el 2 de octubre por el presidente Juan Manuel Santos, dicho Acuerdo fue rechazado por un escaso margen del 50,21\% de los votos. Conscientes de que el rechazo se debió a ciertos términos del Acuerdo y no a la paz, las partes prosiguieron con las negociaciones, con la finalidad de llegar a un nuevo consenso que recogiera las propuestas de aquéllos que habían votado en contra. ${ }^{2}$ En apenas un mes, el 12 de noviembre de 2016, se dio a conocer un nuevo Acuerdo Final para la Terminación del Conflicto y la Construcción de una

La Mesa de Conversaciones se reunió por primera vez el 18 de octubre de 2012 en Oslo, Norueģa. Este esfuerzo del presidente Juan Manuel Santos para poner fin al conflicto le fue reconocido internacionalmente al ganar el Premio Nobel de la Paz el 7 de octubre de 2016. 
Paz Estable y Duradera (en adelante, Acuerdo Final, Acuerdo o AF), firmado el 24 de noviembre de 2016, ${ }^{3}$ que integraba los "cambios, precisiones y aportes de los más diversos sectores de la sociedad" (Comunicado Conjunto No. 4, [en línea]).

El Acuerdo, cuyo objetivo fundamental es "sentar las bases de una paz estable y duradera" (AF, p. 7), se compone de seis puntos ${ }^{4}$ que "constituyen un todo indisoluble" (AF, p. 6). Entre ellos se encuentra el Acuerdo sobre las Víctimas del Conflicto, que regula la creación de un Sistema Integral de Verdad, Justicia, Reparación y No Repetición cuyo objetivo es contribuir "a la lucha contra la impunidad" (AF, p. 8). Si bien son varios los componentes de este complejo Sistema Integral, ${ }^{5}$ en el presente ensayo analizaremos ciertos aspectos de uno de los mecanismos más controvertidos: la Jurisdicción Especial para la Paz (en adelante, JEP) cuya función, como ya se avanzaba el 23 de septiembre de 2015, consistirá en "acabar con la impunidad, obtener verdad, contribuir a la reparación de las víctimas y a juzgar e imponer sanciones a los responsables de los graves delitos cometidos durante el conflicto armado, particularmente los más graves y representativos, garantizando la no repetición" (Comunicado Conjunto No. 60, [en línea]).

Si bien es innegable que la ejecución del Acuerdo "pondrá fin de manera definitiva a un conflicto armado de más de cincuenta años" (AF, p. 4) y que se trata de un progreso que la Fiscalía de la Corte Penal Internacional (en adelante, la Corte o CPI) ha valorado positivamente siempre y cuando "rinda homenaje a la justicia como un pilar fundamental para una paz sostenible" (Declaración de la Fiscal sobre el Acuerdo de creación de una Jurisdicción Especial para la Paz en Colombia), al igual que el Consejo de Seguridad de las Naciones Unidas que lo ha "acogido con beneplácito" (S/RES/2261 (2016)), lo cierto es que subsisten ciertas dudas acerca de las posibilidades del Acuerdo para erradicar la impunidad ${ }^{6}$ en Colombia. ${ }^{7}$

3 El Acuerdo se refrendó en el Senado y en el Congreso los días 29 y 30 de noviembre, respectivamente, y a partir de ese momento está previsto que comience su implementación. El presente artículo se terminó de redactar el 30 de noviembre de 2016 y, por lo tanto, no recoge los acontecimientos que se hayan producido con posterioridad.

4 Hacia un nuevo campo colombiano: Reforma rural inteğral; Participación política: Apertura democrática para construir la paz; Fin del conflicto; Solución al problema de las drogas ilícitas; Mecanismos de implementación, verificación y refrendación; y el Acuerdo sobre las víctimas del conflicto.

5 El Sistema lo forman la Comisión para el Esclarecimiento de la Verdad, la Convivencia y la No Repetición; la Unidad para la Búsqueda de Personas dadas por Desaparecidas en el contexto y en razón del conflicto; las Medidas de reparación inteğral para la construcción de la paz; las Garantías de No Repetición, y, finalmente, la Jurisdicción Especial para la Paz.

6 Situación de impunidad respecto de la comisión de graves violaciones a los derechos humanos y al Derecho internacional humanitario que la Comisión Interamericana de Derechos Humanos (en adelante, ComIDH) ha vuelto a denunciar en su último Informe Anual de 2015 (ComIDH, 2016, p.781). Véase también CESIJ, 2015, p.53.

7 Desde que anunciara la creación de la JEP, el Acuerdo ha suscitado las más variadas reacciones en torno a su conformidad o no con los estándares internacionales. Al inicio, los debates fueron especialmente 
Por ello, en el presente ensayo nos proponemos analizar si el reciente Acuerdo sobre Víctimas es o no un acuerdo de impunidad y si, en definitiva, respeta los estándares establecidos por el Estatuto de Roma de la Corte Penal Internacional (en adelante, ECPI o el Estatuto de Roma). Ante la imposibilidad de analizar en detalle la totalidad del Acuerdo, tras explicar qué es la impunidad desde la perspectiva del Derecho internacional, la relación que existe con la justicia transicional y la influencia que ejerce en estos contextos transicionales la Corte Penal Internacional, nos referiremos a la JEP y nos centraremos en el sistema de imposición de penas previsto en el Acuerdo. Se trata de un tema de actual interés, que trasciende las particularidades del caso colombiano. Y es que, mediante el análisis de Colombia, "se está definiendo con precisión aquellas medidas proscritas por el Derecho Internacional, que no pueden ser objeto de negociación por actores implicados en delitos de lesa humanidad" (Olasolo Alonso, 2014, p. 56). En definitiva, la posición que la Corte mantenga respecto de la imposición de penas sentará, sin lugar a dudas, un importante precedente (Carta de la fiscal de la CPI al presidente de la Corte Constitucional acerca del Marco Jurídico para la Paz, 2013).

\section{La justicia transicional y la erradicación de la impunidad}

Un análisis de las transiciones llevadas a cabo por los diferentes Estados muestra que, históricamente, ha prevalecido la impunidad ${ }^{8}$ (Bonet Pérez y Alija Fernández, 2009, p. 93). Por ello, no es de extrañar que la instauración de la Corte se celebrara como "el acontecimiento más destacado en la larga lucha de la comunidad internacional para hacer avanzar la causa de la justicia” (S/2004/616, p. 19). Si bien el Estatuto de Roma es contundente al afirmar su objetivo primordial de poner fin a la impunidad de los autores de los crímenes internacionales (Preámbulo ECPI), lo cierto es que no define qué es, exactamente, la impunidad. Esta imprecisión se reproduce, con mayor o menor alcance, en la mayoría de instrumentos

controvertidos respecto del régimen de sanciones que preveía (que en el Acuerdo Final se mantiene, prácticamente, inalterado). La Procuraduría General de la Nación declaró que el Acuerdo era un "pacto de impunidad", que no cumplía los estándares internacionales (Carta de Alejandro Ordoñez Maldonado a la Señora Fatou Bensouda), opinión que compartían tanto Amnistía Internacional (2016) como Human Rights Watch (2015). No obstante, esta última ha flexibilizado un tanto su posición en la última carta remitida al presidente Santos (Human Rights Watch, 2016). En el extremo contrario se encontraban expertos como Ambos (Ambos, 2015 y Semana, 2016), Uprimny (2015 y 2016), Bernabeu (ElPaís.com. co, 2016) o Moreno Ocampo (El Tiempo, 2015) que defendían que Colombia estaría cumpliendo sus compromisos internacionales.

8 Para un análisis sobre las formas de impunidad véase Ambos, 1999, pp. 34-43. 
internacionales ${ }^{9}$ y no ha sido tratada de manera homogénea por la jurisprudencia internacional. ${ }^{10}$ Puede que una de las razones que explican las dificultades de concretar el significado de la impunidad se deba al hecho de que nos hallamos ante "un problema de enormes dimensiones que no admite soluciones fáciles o instantáneas" (Chinchón Álvarez, 2007, p. 433).

A nuestro juicio, la definición más completa de impunidad la proporciona el denominado "Conjunto de principios actualizado para la protección y la promoción de los Derechos Humanos mediante la lucha contra la impunidad", elaborado por la experta independiente Diane Orentlicher (en adelante, Conjunto de principios):

La impunidad constituye una infracción de las obligaciones que tienen los Estados de investigar las violaciones, adoptar medidas apropiadas respecto de sus autores, especialmente en la esfera de la justicia, para que las personas sospechosas de responsabilidad penal sean procesadas, juzgadas y condenadas a penas apropiadas, de garantizar a las víctimas recursos eficaces y la reparación de los perjuicios sufridos de garantizar el derecho inalienable a conocer la verdad y de tomar todas las medidas necesarias para evitar la repetición de dichas violaciones (E/CN.4/2005/102/Add.1, Principio 1, [en línea]).

Como se puede apreciar, el procesamiento, enjuiciamiento y condena de los responsables constituye, pese a su centralidad, ${ }^{11}$ únicamente uno de los ejes previstos en el Conjunto de principios para erradicar la impunidad. ${ }^{12}$ Según la definición proporcionada, también es necesario garantizar recursos eficaces, reparación, verdad y adoptar medidas para evitar la repetición de violaciones a los Derechos

9 Compárese el diferente alcance con el que se define la impunidad en: Eradicating impunity for Serious Human Rights Violations, 2011, pp. 6-7; Declaración y programa de acción de Viena, 1993, p.53; African Commission on Human and Peoples' Rights, 87: Resolution on Ending Impunity in Africa and on the Domestication and Implementation of the Rome Statute of the International Criminal Court, 2005; E/CN.4/ RES/2005/81.

10 Véase a este respecto el pormenorizado estudio realizado por Chinchón Álvarez (2012). La Corte Interamericana de Derechos Humanos (en adelante, CorteIDH) entiende por impunidad "la falta en su conjunto de investigación, persecución, captura, enjuiciamiento y condena de los responsables de las violaciones de los derechos proteģidos por la Convención Americana, toda vez que el Estado tiene la obligación de combatir tal situación por todos los medios leģales disponibles ya que la impunidad propicia la repetición crónica de las violaciones de derechos humanos y la total indefensión de las víctimas y de sus familiares" (CortelDH. Caso de la "Panel Blanca" (Paniagua Morales y otros) vs. Guatemala. Fondo, párr. 173). Posición de la CorteIDH respecto de la impunidad que alğunos autores consideran muy ríģida (Dondé Matute, 2010, p. 293).

11 No debemos olvidar que "el enjuiciamiento es uno de los elementos centrales de una estrateģia inteģrada de justicia de transición” (HR/PUB/06/4, p.1).

12 Por ello, en el contexto que nos ocupa, la impunidad "transciende notablemente de la mera ausencia de castiogo" (Chinchón Álvarez, 2012, p. 30). 
Humanos. ${ }^{13}$ Así, cabe concluir que una respuesta eficaz contra la impunidad requiere de la adopción de una estrategia general que contenga medidas complementarias (E/CN.4/2004/88, p. 2). Se trata de adoptar un enfoque global que, incluso, ha recibido el apoyo de la Fiscalía de la Corte (ICC-OPT, 2007, pp. 7-8).

Este conjunto amplio e interrelacionado de medidas coincide con los pilares de lo que se conoce como justicia transicional. ${ }^{14}$ Por ello, defendemos que un proceso íntegro e interrelacionado de este modelo de justicia que aglutine los componentes mencionados puede constituir, de entrada, un instrumento eficaz para erradicar la impunidad. Por esta razón, suscribimos completamente las palabras del Relator Especial sobre la promoción de la verdad, la justicia, la reparación y las garantías de no repetición (en adelante, Relator Especial), cuando insiste en que:

Persisten ciertas ideas erróneas sobre estos mecanismos. El Relator Especial subraya que no se trata de mecanismos creados para establecer una "forma de justicia blanda" ${ }^{15}$ ni como medio para alcanzar el objetivo de la reconciliación eludiendo las cuatro áreas de acción de este mandato (A/HRC/21/46, pp. 6-7).

Con la finalidad de aclarar ciertos conceptos básicos sobre la justicia transicional, nos proponemos analizar, muy brevemente, los ejes básicos sobre los que se sustenta esta modalidad íntegra de justicia.

\section{Breves notas introductorias sobre la justicia transicional}

Los contextos en los que se ha producido un conflicto armado, como el que analizamos en el presente trabajo, hacen parte de las situaciones que pueden "activar" la implementación de un proceso de justicia transicional. ${ }^{16}$ Ahora bien, un proceso que considere como sujeto central a las víctimas ${ }^{17}$-mediante la aplicación

13 Por esta razón, es acertado defender que la impunidad nieģa los derechos de las víctima a la verdad, a la justicia y a la reparación (Odio Benito, 1998, p. 151). Como puede apreciarse, estos derechos "se superponen con el tipo holístico de justicia de transición (...)" (HR/PUB/08/1, p.9). Para un análisis más detallado sobre esta cuestión, consúltese A/RES/60/147.

14 Los fundamentos comunes de la justicia transicional y la lucha contra la impunidad han sido puestos de relieve en $\mathrm{H} / \mathrm{PUB} / 13 / 5$, p. 5 .

15 En el mismo sentido véase Méndez, 2013, p.14.

16 Véase el Informe del Secretario General sobre "El Estado de derecho y la justicia de transición en las sociedades que sufren o han sufrido conflictos" (S/2004/616).

17 La centralidad que deben ostentar las víctimas en la justicia transicional ha sido reivindicada en numerosos pronunciamientos internacionales, entre los que destacamos: A/HRC/RES/18/7, p.3; A/HRC/21/46, p. 17; S/2004/616,p.9; HR/PUB/09/2, p.1. Véase también la posición de la ComIDH sobre la aplicación y el alcance de la Ley de Justicia y Paz (ComIDH, 2006) y en OEA/Ser.L/V/II, p. 141. En la doctrina consúltese Bassiouni (2010, p.16) y Ambos (2009, p. 41). 
complementaria ${ }^{18}$ de mecanismos judiciales y no judiciales ${ }^{19}$ que reconocen los límites intrínsecos de cada una de las medidas por separado ante la comisión de violaciones masivas y sistemáticas a los Derechos Humanos ${ }^{20}-$, tiene como objetivo erradicar la impunidad, garantizando y haciendo efectivos los derechos a la justicia, a la verdad, a la reparación y a la no repetición. ${ }^{21}$

Por las razones expuestas, en este punto, el Acuerdo merece una valoración positiva. Y es que, desde que se acordara la "Declaración de principios para la discusión del Punto 5 de la Agenda: Víctimas", del 7 de junio de 2014, las partes han reconocido los derechos de las víctimas a la justicia, la verdad, la reparación y la no repetición, y así queda reflejado, al menos sobre el papel, en el reciente Acuerdo (AF, p. 127).

Por lo que respecta a la globalidad del proceso de justicia transicional, el propio Acuerdo insiste en que "el Sistema pretende ser integral, para que las medidas logren un máximo de justicia y de rendición de cuentas sobre las violaciones a los Derechos Humanos e infracciones al DIH ocurridas a lo largo del conflicto" (AF, p. 127). Para cumplir este objetivo, el Sistema prevé la combinación de mecanismos judiciales (JEP) y extrajudiciales (Comisión para el Esclarecimiento de la Verdad, la Convivencia y la No Repetición; la Unidad para la Búsqueda de Personas dadas por Desaparecidas en el contexto y en razón del conflicto; las Medidas de reparación integral para la construcción de la paz; y las Garantías de No Repetición) (AF, p. 127).

$\mathrm{Si}$ bien es cierto que el Acuerdo recoge los cuatro componentes básicos de todo proceso de justicia transicional, un análisis más detallado de las relaciones entre los dos mecanismos principales (la Comisión y la JEP) muestra que esta integridad, en realidad, contiene importantes lagunas. El aspecto más criticable ${ }^{22}$ es que

18 Consúltense los siģuientes instrumentos que apoyan la integridad y complementariedad que debe producirse entre los mecanismos transicionales: A/HRC/RES/18/7, pp .2-3; A/HRC/24/46, Punto III.D; HR/ PUB/06/4, p. 10; A/HRC/RES/24/15, p. 3; S/2006/616, p. 6. Léase también el voto concurrente del Juez García - Sayán en el Caso Masacres de El Mozote y Luogares Aledaños vs. El Salvador (párr. 22). En un sentido similar, pero con el foco de atención centrado en las reparaciones, consúltese: CortelDH. Caso de las Comunidades Afrodescendientes Desplazadas de la Cuenca del Río Cacarica (Operación Génesis) Vs. Colombia, párr. 470. Por lo que a la doctrina respecta, debemos subrayar el pronunciamiento de Orentlicher en el que defiende que, con el paso del tiempo, se ha hecho más evidente la necesidad de un acercamiento comprensivo a la hora de hacer frente a los abusos sistémicos cometidos en el pasado (2007,p.16).

19 Véase cómo se recogen estos mecanismos, entre otros, en S/2004/616, p. 6 y A/HRC/RES/21/15, p. 3.

20 Estos límites son puestos de manifiesto en A/HRC/21/46, Punto III.D. Asimismo, el Secretario General de la ONU ha reconocido los límites propios de la justicia penal en S/2004/616, pp. 18-19.

21 Consúltese el contenido de estos derechos en E/CN.4/2005/102/Add.1 y A/RES/60/147. Véase también A/HRC/21/46, p. 7.

22 Tampoco queda clara la relación entre la Comisión y los programas de reparación, si bien no parece deducirse que esta vaya a tener la capacidad de recomendar reparaciones (AF, p. 136). Este aspecto es criticable, ya que se trata de una labor que ha sido asumida por la mayoría de comisiones de la verdad (Hayner, 2014, p. 279). 
se haya acordado que "la información que reciba o produzca la Comisión no podrá ser traslada por esta a autoridades judiciales para ser utilizada con el fin de atribuir responsabilidades en procesos judiciales o para tener valor probatorio; ni las autoridades judiciales podrán requerírsela" (AF, pp. 133-134). A nuestro juicio, deberían de haberse previsto mayores cauces de cooperación y coordinación entre ambos mecanismos; ${ }^{23}$ una relación más fluida y estrecha no sólo evitaría previsibles contradicciones, sino que hubiera agilizado el proceso ante la JEP, ya que, como posteriormente explicaremos, esta prevé un procedimiento especial en el caso de reconocimiento de verdad y responsabilidad (AF, p. 152).

También debemos advertir que la mera inclusión de los ejes básicos de la justicia transicional mediante un sistema integral no es suficiente, puesto que para que los mismos contribuyan a la erradicación de la impunidad, es preciso que en su implementación respeten el alcance previsto por el Derecho Internacional. Así, es fundamental que la complementariedad del sistema creado no permita la compensación de unas medidas con otras (A/HRC/21/46, pp. 9-10) y, especialmente, que no tenga como propósito principal limitar el alcance de la justicia penal. A este respecto consideramos oportuno recordar que, ante la comisión de crímenes internacionales, el Derecho Internacional Penal impone obligaciones contundentes a los Estados en materia de investigación, enjuiciamiento y sanción que, independientemente de las medidas adoptadas sobre verdad, reparación y no repetición, deben satisfacerse atendiendo a los estándares internacionales vigentes. ${ }^{24}$ Es decir, la integridad del proceso transicional no implica que puedan satisfacerse parcialmente las obligaciones internacionales que constituyen la base jurídica de cada uno de los componentes.

Ahora bien, es innegable que los contextos transicionales plantean ciertas dificultades a los Estados a la hora de cumplir con los compromisos asumidos en el ámbito internacional ${ }^{25}$ (A/HRC/27/56, p. 5). Asimismo, debemos tener presente que en muchas ocasiones, tal y como sucede en el caso colombiano, el diseño de la justicia transicional se desarrollará en el transcurso de las negociaciones entre las partes para poner fin a un conflicto armado. ${ }^{26}$

Pese a las particulares circunstancias de estos contextos, lo cierto es que las obligaciones internacionales, en especial la obligación de investigar, enjuiciar y

\footnotetext{
23 Si quiere profundizarse en el estudio de labor que realizan las comisiones de la verdad y la influencia que las mismas han tenido, en muchas ocasiones, en posteriores procesos penales, véase Hayner (2014). Para un mayor análisis sobre la posición del Derecho internacional en la justicia transicional consúltense, entre otros, Chinchón Álvarez (2007), Méndez (2013) y Forcada Barona (2011). el que se desarrolla el proceso de transición. Véase S/2004/616, p. 6.

26 Estas dificultades adicionales se reconocen en OEA/Ser.L/V/II.Doc.49/13, p. 122.
} 
sancionar los crímenes internacionales a los que acabamos de hacer referencia, no prevén excepciones que pudieran justificar un régimen especial, alternativo o atenuado de cumplimiento, ${ }^{27}$ es decir, "no existe, al menos hasta la fecha, ningún régimen jurídico propio a ellos, como tal, ya establecido y que podamos calificar como 'derecho transicional'” (Chinchón Álvarez, 2013, p. 33). Por esta razón, y por el "nivel de madurez jurídica, si no total, sí suficiente" (Vacas Fernández, 2013, p. 542) que ha alcanzado el Derecho Internacional Penal, nos hallamos ante una situación en la que no debemos preguntarnos si se deben cumplir las obligaciones internacionales, sino cómo hacerlo (A/68/345, p. 21).

Es más, Colombia, con la firma y posterior ratificación del Estatuto de Roma, ha asumido unos compromisos adicionales en la lucha contra la impunidad, que en las actuales negociaciones de paz tampoco puede obviar. Por ello, nos parece correcto afirmar que la justicia transicional "encuentra importantes limitaciones en su ámbito de aplicación al fenómeno de la lesa humanidad" (Olasolo Alonso, 2014, p. 55) y respecto de los crímenes internacionales, en general, al tener que respetar los objetivos del ECPI (Stewart, 2015, p. 19), Estatuto que, como a continuación analizaremos, se halla en el centro del debate legal concerniente a la justicia transicional (Schabas, 2011, p. 11).

\section{La CPI y la justicia transicional en Colombia}

La Corte lleva examinando preliminarmente la situación de Colombia desde junio de 2004. ${ }^{28}$ Esta "complementariedad positiva" (ICC-OPT, 2013, pp. 25-26) ha resultado ser un importante instrumento ${ }^{29}$ para que, en las negociaciones de paz, las autoridades colombianas traten de respetar las obligaciones impuestas por el Estatuto de Roma, y así evitar la activación de la competencia de la Corte. Por ello, la compleja cuestión a la que se enfrenta el Estado colombiano es "cómo cumplir los requisitos de justicia previstos en el Estatuto y lograr a la vez paz y estabilidad duraderas" (Stewart, 2015, p. 1) cuando, además, las amnistías respecto de crímenes internacionales y crímenes de guerra se hallan fuera de la mesa de negociación (Roht-Arriaza, 2015, p. 369).

\footnotetext{
27 Como recuerda la ComIDH, nos hallamos ante "la irrenunciabilidad del deber estatal de investigar las graves violaciones de derechos humanos” (ComIDH, Informe Anual 2014, p. 590).

28 Autores como Pigrau Solé (2013) han defendido que "la cantidad y ģravedad de los crímenes cometidos en Colombia en las últimas décadas es de tal maģnitud que resulta muy difícil entender que la Fiscalía de la CPI no haya solicitado todavía la apertura de una investigación" (p. 689).

29 A juicio de Olasolo Alonso (2013), este examen preliminar de la Fiscalía ha tenido "un impacto muy signnificativo sobre las negociaciones de paz entre el Gobierno y las FARC" (p. 734). Impacto que, seguramente, se ha visto influenciado también por el Sistema Interamericano de Protección de los Derechos Humanos que "se erige como actor fundamental de los procesos de transición en Latinoamérica" (Acosta, 2014, p. 295).
} 
A pesar de que se ha defendido que "el Estatuto no es un instrumento dogmático e inflexible, sino flexible y abierto a procesos de paz" (Ambos, 2006, p. 28), lo cierto es que esta "flexibilidad"30 tiene un límite claro que mencionábamos al inicio del ensayo: la erradicación de la impunidad. Por ello, todo acuerdo o proceso de paz que no respete este mínimo debería hacer la situación admisible ante la Corte (art. 17 ECPI).

Dado que, a juicio del Fiscal Adjunto de la Corte, el mandato de ésta se relaciona con el primer elemento de la justicia transicional, es decir, con los juicios penales (Stewart, 2015, p. 5), nos referiremos a esta cuestión a continuación. ${ }^{31}$ Para ello, analizaremos, en primer lugar, en qué consiste la JEP y, posteriormente, nos referiremos al sistema de imposición de penas previsto en el Acuerdo sobre Víctimas.

\subsection{La Jurisdicción Especial para la Paz}

La JEP'2, cuya competencia se extiende a todos aquéllos que participaron directa o indirectamente en el conflicto (AF, p. 148), "es una jurisdicción especial que ejerce funciones judiciales de manera autónoma y preferente sobre los asuntos de su competencia, en especial, respecto a conductas consideradas graves infracciones al Derecho Internacional Humanitario o graves violaciones de los Derechos Humanos" (AF, p.144). Uno de los objetivos que busca la JEP consiste en aplicar una "justicia restaurativa que preferentemente busca la restauración del daño causado y la reparación de las víctimas afectadas por el conflicto" (AF, p. 144).

Llegados a este punto debemos matizar que, sin perjuicio de la centralidad que la justicia transicional debe garantizar a las víctimas, un proceso de transición no debe prescindir de la otra parte fundamental: los responsables de las violaciones que, en determinadas ocasiones, tal y como sucede en el caso colombiano, habrán adquirido la gravedad suficiente como para ser considerados crímenes internacionales. ${ }^{33}$ Por ello, es necesario analizar cómo se regula el proceso ante la JEP para comprobar si se respetan los estándares internacionales o si, por el contrario, las partes han tratado de atenuar la responsabilidad internacional penal de los individuos.

\footnotetext{
30 Flexibilidad que ha sido apoyada por el Fiscal Adjunto de la Corte (Stewart, 2015, p. 18).

31 Hay quien va más allá y defiende que la Corte es parte del proyecto de la justicia transicional (Moreno Ocampo, 2007, p. 8). Puede que ésta sea la razón por la que determinados expertos aróumentan que el trabajo de la Corte no puede seguir considerándose como un mecanismo separado de justicia aplicable tras los conflictos (Bassiouni, 2010, p. 25).

Los objetivos de la JEP son: "satisfacer el derecho de las víctimas a la justicia, ofrecer verdad a la sociedad colombiana, proteger los derechos de las víctimas, contribuir al loģro de una paz estable y duradera, y adoptar decisiones que otorģuen plena seguridad jurídica a quienes participaron de manera directa o indirecta en el conflicto armado interno, respecto a hechos cometidos en el marco del mismo y durante este que suponģan graves infracciones del Derecho Internacional Humanitario y graves violaciones de los Derechos Humanos" (AF, p.143).

Véase, entre otros, el Informe Preliminar de la Corte de 2015, p. 7.
} 
El sistema creado por la JEP bien merece el calificativo de complejo, no sólo por las numerosas salas que creará o los diversos procedimientos que prevé, ${ }^{34}$ sino por su interrelación con el resto de componentes de verdad, reparación y no repetición ${ }^{35}$ y la participación que en ella otorga a las víctimas. ${ }^{36}$

Respecto de los procedimientos regulados, resulta relevante mencionar que prevé un tratamiento diferenciado en función de si el autor reconoce o no la responsabilidad por los hechos ilícitos cometidos y de la revelación que realice sobre los mismos. El Acuerdo se refiere a estos extremos como "procedimiento en caso de reconocimiento de verdad y reconocimiento de responsabilidad" y "procedimiento en caso de ausencia de reconocimiento de verdad y de responsabilidad” (AF, p. 152). Independientemente de las particularidades y notables diferencias, ambos tienen un elemento en común: la priorización que permiten respecto de los casos más graves y representativos. ${ }^{37} \mathrm{Si}$ bien esta política de selección de casos es aplicada por los tribunales penales internacionales creados hasta el momento, también por la CPI, tal y como lo han señalado tanto la $\mathrm{ComIDH}^{38}$ como la CorteIDH ${ }^{39}$, la aplicación de una estrategia de priorización a nivel interno podría ser incompatible con los estándares internacionales. Es más, sobre este extremo se ha pronunciado la CPI en numerosas ocasiones y ha advertido que dicha priorización podría conllevar la activación de su competencia. ${ }^{40}$

Si bien deberemos esperar al desarrollo e implementación práctica de estas disposiciones, con la información de la que disponemos no consideramos que la estrategia de selección de casos sea el factor principal que pueda llegar a activar la competencia de la Corte. ${ }^{41}$ A nuestro juicio, el aspecto más controvertido del

34 Consúltese el apartado III del Acuerdo Final (pp.152-175) si se desea realizar un mayor análisis.

35 Consúltese el AF, p.145 que exiǵe como requisito para participar en el réǵimen especial "aportar verdad plena, reparar a las víctimas y garantizar la no repetición".

36 Léase el AF, p.147 que, entre otros, obliģa a que las víctimas sean "oídas en los supuestos de priorización y selección de casos".

37 Pueden compararse las previsiones de los Puntos 480) y s); 50c) y g)); 51d) del Punto III del Acuerdo Final (pp. 154-159).

38 Véase, entre otros, OEA/Ser.L/V/II. Doc.49/13, p.157 así como el Informe Anual 2015, p. 786.

39 En 2007, la CortelDH determinó que "si bien existen alģunas investiģaciones y condenas, subsiste la impunidad en el presente caso, en la medida en que no ha sido determinada toda la verdad de los hechos ni la totalidad de las responsabilidades por los mismos" (Caso de la Masacre de La Rochela vs. Colombia, párr. 178).

40 En el Informe intermedio sobre la situación en Colombia del año 2012 la Corte declaró que "la priorización de casos para determinar la admisibilidad ante la CPI no debe conllevar impunidad por otros crímenes" (p. 65). A lo que añadió que "no examinar esa información podría afectar neģativamente los esfuerzos de un Estado de llevar a cabo actuaciones auténticas respecto de los máximos responsables de los crímenes más ğraves" (p. 67).

41 Este extremo no se halla exento de debate, ya que, como ha advertido el Relator Especial, preocupa "que se utilice el principio de complementariedad como "licencia para el minimalismo" que aumenta, en luģar de reducir, la impunidad" (A/HRC/27/56, p. 13). 
Acuerdo se halla en el régimen de sanciones especiales que impondrá la JEP y al que a continuación nos referiremos.

\subsection{Las sanciones especiales y los límites impuestos por el Derecho Internacional}

El Acuerdo establece que los crímenes que no sean amnistiables, entre los que se encuentran los crímenes internacionales (AF, p. 151), serán investigados y enjuiciados en la JEP (AF, p. 148), mediante un procedimiento complejo que culminará con el establecimiento de una sanción ${ }^{42}$ (pp. 148 y 159). Recordando que nuestro análisis se limita a quienes sean considerados los máximos responsables de haber cometido los crímenes internacionales más graves, a continuación analizaremos las sanciones aplicables a quienes "reconozcan verdad exhaustiva, detallada y plena en la Sala de reconocimiento de verdad y responsabilidades" (AF, p. 172). El Acuerdo prevé que estas sanciones respecto a determinadas infracciones muy graves tendrán un mínimo de duración de cumplimiento de las funciones reparadoras y restauradoras ${ }^{43}$ de la sanción de cinco años y un máximo de ocho años. ${ }^{44}$ El período máximo de cumplimiento de sanciones propias, por la totalidad de las sanciones impuestas, incluidos los concursos de delitos, será de ocho años. ${ }^{45}$

42 El Acuerdo precisa que la imposición de cualquier sanción "no inhabilitará para la participación en política ni limitará el ejercicio de ningún derecho, activo o pasivo, de participación política” (p. 150). Es decir, incluso en el hipotético supuesto de que un máximo responsable (al no haber reconocido verdad y responsabilidad) sea condenado por haber cometido un crimen internacional a la pena privativa de libertad máxima prevista, no verá menoscabamos sus derechos políticos. Ello va en contra de numerosos pronunciamientos internacionales que se oponen a que los responsables de haber cometido crímenes internacionales se mantengan en puestos de autoridad pública (Véanse, entre otros: E/CN.4/RES/2005/81, pp. 4-5; HR/PUB/06/5, pp. 21-22) o que prevén la remoción de los caróos públicos como parte integrante de un proceso de justicia transicional que complemente los límites de la justicia penal (Véanse, entre otros: E/CN.4/2005/102, p.32; HR/PUB/06/5, p. 5).

43 El listado de trabajos, obras y actividades abarca materias tan variadas como, por ejemplo, la participación en programas de reparación efectiva para los campesinos desplazados, programas de protección medioambiental o ejecución de programas de desarrollo urbano (Consúltese el listado completo en las páginas 173-174). Si bien el contenido concreto de la sanción se precisará en las resoluciones y sentencias que imponģa la JEP (p. 166) es pertinente añadir que el Acuerdo permite a los responsables presentar "un proyecto detallado, individual o colectivo, de ejecución de los trabajos, obras o actividades reparadoras y restaurativas" (p. 172) si bien, en última instancia, es el Tribunal quien lo deberá aprobar (p. 172).

44 La valoración de la sanción a imponer deberá tener en cuenta "el grado de verdad otorgado por la persona, la gravedad de la conducta sancionada, el nivel de participación y responsabilidad, las circunstancias de mayor y menor punibilidad, y los compromisos en materia de reparación a las víctimas y ģarantías de no repetición" (AF, p. 171).

45 El Acuerdo contempla la posibilidad de que el período de cumplimiento de la sanción no respete los mínimos y máximos previstos al añadir que "podrá definirse que su ejecución se efectúe durante un periodo preestablecido o bien atendiendo a resultados, como por ejemplo, la culminación de la construcción de una infraestructura determinada, sin perjuicio de la duración de la sanción impuesta por el tribunal en su caso" (AF, p. 172). Es más, “el período de permanencia en las Zonas Veredales Transitorias de Normalización (ZVTN), será considerado en su caso como tiempo de cumplimiento de la sanción, siempre que durante dicha permanencia se hubieran realizado trabajos u obras, o actividades con contenido reparador" (AF, p. 166). 
Comprenderán restricciones efectivas de libertades y derechos, tales como la libertad de residencia y movimiento, que sean necesarias para su ejecución ${ }^{46} \mathrm{y}$, además, deberán garantizar la no repetición (AF, p. 164).

Ante sanciones como las previstas, debemos determinar si el Derecho Internacional Penal permite la imposición de penas restaurativas y sumamente atenuadas a los máximos responsables condenados por la comisión de crímenes internacionales por el hecho de haber reconocido verdad, asumir su responsabilidad y comprometerse a reparar a las víctimas y a garantizar la no repetición. Se trata de un debate que hasta ahora se planteaba en términos meramente especulativos ${ }^{47}$ y que implica reflexionar acerca de si un "castigo flexible" puede convertirse en la más reciente modalidad de impunidad (Roht-Arriaza, 2015, p. 382).

De entrada, debemos señalar que el Conjunto de principios actualizados en el que nos hemos basado para extraer los ejes de la justicia transicional exige que las penas sean apropiadas (p. 6) y que los autores sean condenados debidamente ${ }^{48}$ (Principio 19) ${ }^{49}$. También el Relator Especial ha manifestado que "la imposición de penas poco severas que no sean proporcionales a las pruebas (...) erosiona aún más la fiabilidad del sistema judicial" (A/HRC/27/56, p. 8). Por ello, en procesos de justicia transicional, la proporcionalidad de la pena ${ }^{50} \mathrm{o}$ la coherencia en las condenas ${ }^{51}$ parece ser un requisito ineludible. En consecuencia, puede deducirse que

46 El Acuerdo aclara que "restricción efectiva signnifica que haya mecanismos idóneos de monitoreo y supervisión para ģarantizar el cumplimiento de buena fe de las restricciones ordenadas por el Tribunal (...) condiciones que en ningún caso se entenderán como cárcel o prisión ni adopción de medidas de aseģuramiento equivalentes" (AF, p. 164). Asimismo, reģula los criterios que deben ser aplicados por los maģistrados. Entre los más trascendentales se encuentran: la fijación de los espacios territoriales concretos donde se ubicarán los sancionados durante los periodos de ejecución y cumplimiento de la sanción, la fijación de los horarios de cumplimiento de las sanciones, el réģimen de desplazamientos durante el periodo de ejecución de la sanción, el lugar de residencia de la persona durante la ejecución de la sanción o la periodicidad con la que deberá rendir informes al órģano encarģado de la verificación de la ejecución de la sanción (p. 165). Si bien parece desprenderse que el régimen de desplazamientos estará sujeto a monitorización (p. 166), el resto de criterios continúan siendo imprecisos y podrían suģerir que las restricciones fijadas por la JEP únicamente se limitarán a los periodos de ejecución efectiva de la sanción. Este extremo ha sido denunciado por Human Rights Watch (2016).

47 Como ya advirtió Ambos (2009), "a pesar de la enorme importancia práctica de las exenciones de persecución penal dentro del marco de la justicia de transición, la práctica y el debate corriente padecen la falta de reglas y criterios claros que ayuden a reconciliar la paz y la justicia en situaciones de transición" (p.34). Véanse también las aproximaciones que sobre la reducción, la suspensión y las alternativas a la sanción realizó el Fiscal Adjunto de la Corte (Stewart, 2015, pp. 10-14).

48 En el mismo sentido véase $\mathrm{A} / \mathrm{HRC} / 18 / 23$, p. 9.

49 Precisa que "la revelación sólo puede ser causa de reducción de la pena para contribuir a la manifestación de la verdad" (Principio 28). En el mismo sentido: HR/PUB/09/1 especifica que "la plena revelación que haģa el autor de lo que sabe acerca de esas violaciones puede justificar una reducción de la pena, siempre que la sentencia siģa siendo proporcional a la ģravedad del crimen" (p. 34).

50 Véase E/CN.4/RES/2005/81, p. 4.

51 Véase HR/PUB/06/4, pp. 29-30. 
para los menores infractores o respecto de crímenes menores sí que podrían preverse medidas con un componente más reparador. ${ }^{52}$

Por lo que al Derecho convencional respecta, es cierto que los tratados internacionales no prevén la sanción que corresponde ante la violación de las conductas que regulan. Ahora bien, precisan que las sanciones han de ser "adecuadas", 53 "eficaces", ${ }^{54}$ "apropiadas", ${ }^{55}$ e incluso, "severas", ${ }^{56}$ Frente a términos tan imprecisos, la jurisprudencia internacional resulta imprescindible para limitar la discrecionalidad de los Estados en su interpretación. Si nos ceñimos al ámbito interamericano, la Corte IDH ha fallado en numerosas ocasiones ${ }^{57}$ que los Estados deben asegurar que "las penas impuestas y su ejecución no se constituyan en factores de impunidad, tomando en cuenta varios aspectos como las características del delito y la participación y culpabilidad del acusado" (Caso Manuel Cepeda Vargas Vs. Colombia, párr.150). Así, los pronunciamientos que exigen que la pena sea apropiada, proporcionada y que eviten medidas ilusorias son una constante en su jurisprudencia ${ }^{58}$. En definitiva, a juicio de la CorteIDH son necesarias penas que "verdaderamente contribuyan a prevenir la impunidad" (Caso Heliodoro Portugal Vs. Panamá, párr. 203).

Mayor claridad ofrecen los Estatutos de los tribunales penales creados hasta el momento en el ámbito internacional, ya que estos, sin excepción, limitan la sanción a imponer a la pena privativa de libertad, ${ }^{59}$ siendo la gravedad del crimen

52 En este sentido, entre otros, S/2011/634, p. 12; HR/PUB/06/4, pp. 9-10; HR/PUB/06/1, pp. 12-13; E/ CN.4/2004/88, p. 8.

53 Véanse, por ejemplo, el IV Convenio de Ginebra relativo a la protección debida a las personas civiles en tiempo de guerra, del 12 de aģosto de 1949 (art.146) y la Convención contra la tortura y otros tratos o penas crueles, inhumanos o deģradantes, del 10 de diciembre de 1984 (art.4).

54 Véase el Convenio para la prevención y castigo del delito de genocidio, del 9 de diciembre de 1948 (art.V).

55 En este sentido: Convención internacional para la protección de todas las personas contra las desapariciones forzadas, del 20 de diciembre de 2006 (art. 7.1) y la Convención interamericana sobre desaparición forzada de personas, del 9 de junio de 1994 (art. III).

56 Este es el caso de la Convención interamericana para prevenir y sancionar la tortura, del 9 de diciembre de 1985 (art.6).

57 No obstante, el voto concurrente del Juez Diego García-Sayán en el caso de Masacres de El Mozote y Luogares Aledaños vs. El Salvador, parece alejarse de esta jurisprudencia (Voto Concurrente al Caso de Masacres de El Mozote y Luģares Aledaños vs. El Salvador, párr. 30-31).

58 Véanse, entre otros, Caso Manuel Cepeda Vargas Vs. Colombia, párr. 153; Caso de la Masacre de La Rochela Vs. Colombia, párr. 193 y 196; Caso Rodríguez Vera y otros (Desaparecidos del Palacio de Justicia) Vs. Colombia, párr. 459.

59 Estatuto del Tribunal Penal Internacional para la antigua Yugososlavia (ETPIY) art. 24; Estatuto del Tribunal Penal Internacional para Ruanda (ETIPR) art. 23; Salas Extraordinarias para el Enjuiciamiento según el derecho camboyano de los crímenes cometidos durante el período de Kampuchea Democrática, art. 38; Estatuto del Tribunal Especial para el Líbano (ETEL) art. 24; Estatuto de las Salas Africanas Extraordinarias, art. 24. Especialmente pertinente para el caso que nos ocupa es el del Estatuto del Tribunal Especial para Sierra Leona, ya que en el caso de los menores de 15 años permite la sustitución de la pena privativa de libertad por penas alternativas (ETESL arts. 7 y 15). No obstante, para el resto de supuestos, únicamente prevé la pena privativa de libertad (art. 19). 
cometido el elemento que determina la duración de la misma. ${ }^{60}$ Por ello, puede deducirse que, ante crímenes internacionales, la proporcionalidad ${ }^{61}$ o la obligación de imponer penas "apropiadas"62 demanda determinado grado de severidad que, hasta ahora, sólo se ha reflejado en las penas de prisión. Por esta razón, no es de extrañar que los códigos penales de los Estados, conscientes de la especial gravedad que supone la comisión de un crimen internacional, sancionen a los responsables con las penas más severas. ${ }^{63}$

\subsection{Las sanciones especiales y la posible activación de la competencia de la CPI}

Si nos centramos en el Estatuto de Roma podemos apreciar que el propio Preámbulo afirma que "los crímenes más graves de trascendencia para la comunidad internacional en su conjunto no deben quedar sin castigo"(1998, [en línea]). No obstante, no precisa qué tipo de castigo se hallan obligados a imponer los Estados a la hora de ejercer su jurisdicción sobre crímenes internacionales (art. 80) ni cuáles son los objetivos de la condena (Schabas, 2011, p. 333). A pesar de ello, es relevante señalar que la Corte únicamente se halla legitimada para imponer las penas previstas en el propio Estatuto (art. 23) que se limitan a la reclusión (art. 77) valorando, a la hora de determinar la misma, factores como la gravedad del crimen o las circunstancias personales del condenado (art. 78) u otras atenuantes (Regla 145 de las Reglas de procedimiento y prueba).

Las sentencias dictadas hasta la fecha por la CPI permiten comprobar que la proporcionalidad o la adecuación de la pena es un factor en el que se basa la Corte para graduar la sanción. ${ }^{64}$ Por ello, tras recordar que ejerce su jurisdicción "sobre personas respecto de los crímenes más graves de trascendencia internacional" (art. 1 ECPI), no duda en declarar que las sanciones deben reflejar la gravedad del crimen por el que han sido acusadas (ICC-01/12-01/15, p. 35) y que, en consecuencia,

60 TIPY, art. 24; TIPR, art. 23; Paneles especiales para el enjuiciamiento de delitos graves en Timor-Leste, art. 10; ETESL, art. 19; ETEL, art. 24.

61 El Proyecto de Crímenes Contra la Paz y la Seguridad de la Humanidad de 1996 también establecía que las penas debían ser proporcionales a la naturaleza y a la gravedad del crimen cometido (art. 3).

62 Estas directrices continúan siendo plenamente viģentes en la actualidad, ya que tal y como insiste el reciente Texto de los proyectos de artículos sobre los crímenes de lesa humanidad aprobados provisionalmente por la Comisión de Derecho Internacional, este tipo de crímenes han de ser "castiģados con penas apropiadas que tenģan en cuenta su gravedad" (art. 5.6).

63 Resulta relevante añadir que, en 1996, la Sala de Primera Instancia del TIPY determinó que "there is a general principle of law common to all nations whereby the severest penalties apply for crimes against humanity in national leģal systems" (IT-96-22-T, párr. 31). Para un análisis comparativo sobre las sanciones previstas en los códigos penales de un número considerable de Estados, véase la base de datos del Comité Internacional de la Cruz Roja: https://ihl-databases.icrc.orģ/applic/ihl/ihl-nat.nsf/vwLawsByCountry.xsp?xp_topicSelected=GVAL-992BU6 (consultado por última vez el 30/11/2016).

64 Véase: ICC-01/04-01/06-2901; ICC-01/04-01/07-3484; ICC-01/05-01/08-3399; ICC-01/12-01/15. 
demandan la pena más severa ${ }^{65}$ (ICC-01/04-01/07-3484, p. 19). Incluso ha afirmado que la imposición de una sentencia que sea proporcionada reconoce el sufrimiento de las víctimas y promueve el restablecimiento de la paz y la reconciliación (ICC01/12-01-15, p. 33). ${ }^{66}$

Atendiendo a diversos pronunciamientos provenientes de diferentes autoridades de la CPI, podríamos concluir que el Estatuto también exige a los Estados un mínimo de severidad y proporcionalidad en la imposición de las penas. ${ }^{67} \mathrm{Y}$ es que, como ya adelantó el Fiscal Adjunto de la Corte, la evaluación de la actuación genuina por parte de los Estados abarca todas las etapas de los procesos e influye sobre la pena impuesta (Stewart, 2015, p. 10).

Por ello, es relevante señalar que cuando la Fiscalía de la Corte se comprometió a examinar la cuestión de las sentencias (Informe Intermedio, 2012, p. 67), no sólo concluyó que la suspensión de las penas a nivel interno irían en contra del Estatuto de Roma al impedir el castigo de los responsables (Carta de la Fiscal, 2013), sino que añadió que "una condena que sea grosera o manifiestamente inadecuada, teniendo en cuenta la gravedad de los delitos y la forma de participación del acusado, invalidaría la autenticidad del proceso judicial, aun cuando las etapas previas del proceso hayan sido auténticas" (Carta de la Fiscal, 2013). Aclaró que "la duración de la pena de prisión puede ser un factor relevante en los casos en los que la pena resulta tan desproporcionada que se puede cuestionar la intención de someter a la persona a la acción de la justicia" (Carta de la Fiscal, 2013). Y, precisamente, sobre este extremo ya ha advertido a Colombia (Informe Preliminar, 2014, p. 15). Es más, el 1 de septiembre de 2016 no dudó en afirmar que la rendición de cuentas "por definición incluye sanciones efectivas" (Declaración de la Fiscal sobre el Acuerdo de creación de una Jurisdicción Especial para la Paz en Colombia).

Por todo ello, nos parece criticable que, en el último Informe sobre las actividades de examen preliminar, la Fiscalía no se pronunciara sobre las sanciones especiales previstas en el Acuerdo $;{ }^{68}$ simplemente se limitó a declarar que "en esta etapa

65 Traducción del inģlés. "Heaviest sentence" en el orioginal.

66 En términos similares véase ICC-01/04-01/07-3484, pp. 17-18

67 A juicio de Seils (2015), "aunque los Estados no están oblighados a dictar sentencias similares a las que establece el Estatuto de Roma, sí se les exiģe cumplir con sus obliģaciones preexistentes en materia de derechos humanos, una manera de garantizar que no se imponģan sentencias ilusorias" (p. 5). Por el contrario, hay quien afirma que no parece existir una teoría del castigo que reclame determinado nivel de severidad en la pena respecto de los crímenes internacionales (De Guzman, 2014, p. 2).

68 El Informe se publicó el 14 de noviembre de 2016 y, en consecuencia, la Fiscalía no pudo valorar el nuevo Acuerdo Final que se dio a conocer ese mismo día. Por ello, examinó "las disposiciones del Acuerdo sobre las Víctimas del Conflicto, concluido entre el Gobierno de Colombia y las FARC-EP en diciembre de 2015" (Informe Preliminar, 2016, párr. 252). No obstante, es criticable la ausencia de un pronunciamiento al respecto ya que, incluso en dicho Acuerdo, se contemplaban las polémicas sanciones especiales que, como puede comprobarse, se han mantenido sin apenas modificaciones en el Acuerdo Final. 
del examen preliminar, la Fiscalía no ha adoptado una posición especifica o final respecto de la Jurisdicción Especial para la Paz, la cual todavía no ha entrado en funcionamiento" (Informe Preliminar, 2016, párr. 257). ${ }^{69}$ Ahora bien, advirtió que el cumplimiento de los objetivos de la JEP “no dependerá únicamente de los procedimientos y condiciones establecidos en el Acuerdo, sino también de la efectividad de las restricciones a la libertad impuestas sobre los individuos, cuya naturaleza aún debe precisarse claramente" (párr. 257).

Si bien es cierto que el desarrollo legislativo e implementación posterior del Acuerdo Final precisará muchos de los aspectos que estamos analizando, lo que es indiscutible es que el régimen de sanciones especiales previsto para los mayores responsables de haber cometido los crímenes internacionales más graves que reconozcan verdad y asuman su responsabilidad, salvo que se produzca un giro de $180^{\circ}$, consistirán en sanciones alternativas y atenuadas. Por ello, ¿cómo debemos interpretar la ausencia de condena expresa de la Fiscalía? ¿Está avalando el sistema creado, a pesar de todos los pronunciamientos en sentido contrario realizados por su Oficina hasta el momento? ¿A pesar de que los tratados internacionales establecen que las penas han de ser adecuadas, eficaces, apropiadas o severas, y de la abundante jurisprudencia internacional que se pronuncia en los mismos términos? ¿A pesar de que los Estatutos de los tribunales penales internacionales creados hasta el momento, también el ECPI, limitan la pena a imponer por crímenes internacionales a la pena privativa de libertad y reiteran en su jurisprudencia la proporcionalidad que debe ser exigida? ¿A pesar de que los Estados, en sus legislaciones internas, han seguido una práctica general, constante y uniforme a la hora de sancionar mediante las penas más severas los crímenes internacionales, que incluso podría sugerir que nos hallamos ante una costumbre internacional? A pesar de todo ello, ¿debemos entender que, a partir de ahora, para los condenados como mayores responsables de haber cometido un crimen internacional, por haber reconocido verdad y su responsabilidad, una sanción efectiva consiste en la imposición de una pena reparadora y restauradora por un período de cinco a ocho años? En definitiva, ante el novedoso sistema creado en Colombia, no podemos sino preguntarnos dónde se halla el límite entre una sanción leve y la impunidad.

69 La Fiscalía concluye que continuará revisando "cuidadosamente todo cambio posible en el texto del acuerdo firmado en 26 de septiembre de 2016 (...) así como todo proyecto leģislativo posterior relativo al establecimiento de mecanismos de rendición de cuentas para los máximos responsables por los crímenes más graves" (párr. 263). 


\section{Conclusiones}

Comenzábamos el presente ensayo defendiendo que un proceso integral de justicia transicional que contemplara mecanismos judiciales y no judiciales que se complementasen entre sí con la finalidad de garantizar los derechos de las víctimas, y que mantuviera un compromiso claro con la investigación, enjuiciamiento y sanción de los responsables de crímenes internacionales, se constituía en un instrumento, de entrada, eficaz a la hora de erradicar la impunidad. Aclarábamos que el mero hecho de elaborar una estrategia global no era suficiente, ya que era preciso que, en su implementación, se respetasen los mínimos exigidos por el Derecho Internacional. También advertíamos que era fundamental que no hubiera intentos de limitar unos mecanismos bajo el pretexto de apoyar o de otorgar mayor protagonismo a otros. Pues bien, sin perjuicio de que el Acuerdo suponga un avance de enorme envergadura para poner fin a un conflicto armado de más de cincuenta años con el que las partes se han comprometido y con el que muestran su voluntad de reparar a las miles de víctimas del conflicto, consideramos que esta primera aproximación al complejo sistema previsto muestra ciertas lagunas que pueden hacer peligrar el objetivo primordial de la justicia transicional y conllevan a que se asimile a esa justicia laxa que tanto se teme y a la que nos oponemos.

$\mathrm{Y}$ es que, bajo el reiterado reconocimiento de los derechos de las víctimas y del eterno debate de paz vs. justicia, se puede apreciar un cierto intento de limitar la responsabilidad penal de los máximos responsables de haber cometido los más graves crímenes internacionales, no sólo por no garantizarse completamente la integridad del Sistema, por la aplicación de una "justicia restaurativa" respecto de crímenes internacionales o por la "selección de casos" que podría llegar a producirse ante la JEP. A nuestro juicio, el conflicto principal se halla en las sanciones "especiales" previstas en el Acuerdo. Consideramos que la imposición de condenas meramente restaurativas y sumamente atenuadas por la comisión de crímenes internacionales por parte de los mayores responsables, independientemente de su reconocimiento de verdad y responsabilidad, no es sino un mero cálculo de oportunidad política que podría no respetar el Derecho Internacional.

Ahora bien, queremos aclarar que en ningún caso nos oponemos a que las penas, como medida integrante de un proceso global de justicia transicional que interrelacione diferentes mecanismos, puedan consistir en alternativas a la prisión o que se impongan sanciones más reducidas, siempre y cuando éstas sigan manteniendo cierto grado de proporcionalidad tanto respecto del crimen cometido como del nivel de responsabilidad del autor. Por esta razón, cuando nos hallamos ante personas condenadas por ser los máximos responsables de un crimen internacional, 
parece lógico que deba exigirse un determinado nivel de severidad en la sanción. Hasta ahora, la única que ha reflejado esta especial gravedad ha sido la pena privativa de libertad y, objetivamente, así puede comprobarse si atendemos a la práctica seguida desde que surgiera el Derecho Internacional Penal. Es más, así lo prevé también el Código Penal de Colombia. Ahora bien, ello no obsta a que sea legítimo, $\mathrm{y}$ tal vez conveniente, iniciar un debate profundo y serio en torno a si, en procesos de justicia transicional, podrían llegar a ser viables otra serie de sanciones que, en última instancia, reflejen la gravedad del ilícito cometido. Y es que, insistimos, la respuesta del Derecho Internacional es contundente: debe garantizarse que las sanciones sean adecuadas, eficaces, apropiadas y, sobre todo, proporcionales a la gravedad del crimen cometido.

Precisamente, por no respetar estos mínimos, consideramos que las sanciones que impondrá la JEP a aquéllos que sean considerados los máximos responsables de haber cometido los crímenes internacionales más graves no es conforme con el Derecho Internacional, pues, en esta ocasión, Colombia ha ido demasiado lejos con el tipo de sanciones reparativas previstas al consistir en "alternativas reducidas" y que encuentra su máxima extralimitación al permitir que incluso puedan ser los responsables quienes propongan el proyecto a realizar, que es tanto como permitir al condenado que elija la pena que desea cumplir. Es importante insistir en que el debate trasciende al de la mera ausencia de penas de cárcel. Y es que, incluso si llegáramos a aceptar la imposición de sanciones con un componente más "restaurador", la proporcionalidad debería estar garantizada. Es decir, resulta imperativo adecuar la sanción al ilícito perpetrado y, a nuestro juicio, esta circunstancia no se produce en el presente caso. Consideramos que muchos de los trabajos o proyectos que se recogen en el Acuerdo no reflejan la gravedad de los crímenes internacionales cometidos. Tampoco lo demuestra el hecho de que la duración en el cumplimiento de la sanción pueda ser inferior a los cinco años. El todavía impreciso régimen de residencia y desplazamientos o la posibilidad de ejercer cargos públicos aun cuando se está cumpliendo una condena por haber sido declarado responsable de un crimen internacional, no hacen sino confirmar la desproporción entre el crimen cometido y la sanción impuesta.

En definitiva, no creemos que el sistema de sanciones previsto para los mayores responsables de haber cometido los más graves crímenes internacionales que reconozcan verdad y responsabilidad se adecúe al Estatuto de Roma y, por ello, creemos que este hecho provocaría la admisibilidad de la situación ante la Corte (art. 17 y 20 ECPI). Ahora bien, independientemente de que se cumplan los requisitos para que la Corte ejerza su jurisdicción, la CPI siempre podrá valorar la incidencia que el 
presente Acuerdo tendrá en el fin del conflicto y que le podría llevar a alegar el escurridizo "interés de la justicia" (art. 53.1c) evitando así su intervención en Colombia. No obstante, si procediera de dicha manera, se crearía un precedente que podría conllevar la revisión del conjunto del sistema de justicia penal internacional.

La razón reside en que los casos que demandan la implementación de procesos de justicia transicional son aquéllos en los que se han cometido violaciones masivas y sistemáticas a los Derechos Humanos que, obsérvese, son los que normalmente activarán la competencia de la Corte. Por ello, podría defenderse que los casos en los que actualmente está ejerciendo su jurisdicción la Corte requieren la implementación de estrategias globales que interrelacionen varios mecanismos transicionales y complementen los límites de la justicia penal. De ser así, llegaríamos a la conclusión de que los casos enjuiciados por la Corte podrían ser también casos de justicia transicional y, de seguir el precedente colombiano, concluiríamos que en el caso de que el Estado implementase un proceso íntegro de justicia transicional resultaría admisible la imposición de sanciones alternativas y atenuadas para los máximos responsables de haber cometido los más graves crímenes internacionales.

Odio Benito declaró que "los aportes del Estatuto de Roma y de la jurisprudencia de la Corte Penal Internacional a la justicia en transición apenas empiezan, los cambios estructurales profundos aún están por ocurrir” (Odio Benito, 2009, p. 254). Nosotros no tenemos ninguna duda de que con el Acuerdo sobre víctimas esa oportunidad ha llegado. Es el momento de decidir el tipo de cambios que el sistema de Justicia Penal Internacional está dispuesto a asumir y, ahora, esa decisión se encuentra en manos de la Corte Penal Internacional.

\section{Referencias}

Acosta, P. A. (2014). De la ductilidad y otras angustias: los retos de la justicia interamericana en materia de justicia transicional. Foro Nueva época., 17 (1). Recuperado de http://revistas.ucm.es/index.php/FORO/article/ view/48622/45411

Ambos, K. (1999). Impunidad y Derecho Penal Internacional. Buenos Aires: Ad-Hoc. Ambos, K. (2006). Temas de Derecho Penal Internacional y Europeo. Madrid: Marcial Pons.

Ambos, K. (2009). El marco jurídico de la justicia de transición. En K. Ambos, E. Malarino, \& G. Elsner (Eds.), Justicia de transición: Informes de América Latina, Alemania y España (pp. 23-132). Montevideo: Fundación Konrad-Adenauer. Recuperado de http://www.kas.de/wf/doc/kas_18236-544-4-30.pdf 
Bassiouni, M. C. (2010). Assessing Conflict Outcomes: Accountability and Impunity. En M. C. Bassiouni (Ed.), The Pursuit of International Criminal Justice: A World Study on Conflicts, Victimization, and Post-Conflict Justice. Antwerp, Oxford, Portland: Intersentia.

Bonet Pérez, J., \& Alija Fernández, R.A. (2009). Impunidad, derechos humanosyjusticia transicional. Bilbao: Cuadernos Deusto de Derechos Humanos Núm. 53.

Chinchón Álvarez, J. (2007). Derecho internacional y transiciones a la democracia y la paz: Hacia un modelo para el castigo de los crímenes pasados a través de la experiencia iberoamericana. Sevilla: Parthenon.

Chinchón Álvarez, J. (2012). El concepto de impunidad a la luz del Derecho internacional: una aproximación sistémica desde el Derecho internacional penal y el Derecho internacional de los derechos humanos. Revista Electrónica de Estudios Internacionales, 24. Recuperado de http://www.reei.org/index. php/revista/num24/articulos/concepto-impunidad-luz-derecho-internacional-una-aproximacion-sistemica-desde-derecho-internacional-penal-derecho-internacional-derechos-humanos

Chinchón Álvarez, J. (2013). El binomio justicia transicional - Derecho transicional. Un examen a propósito de algunas reflexiones teóricas y prácticas recientes. En Actas V Jornadas de estudios de seguridad. Instituto Universitario General Gutiérrez Mellado de Investigación sobre la Paz, la Seguridad y la Defensa. Recuperado de http://eprints.sim.ucm.es/22722/1/ARTICULO_ EN_ACTAS_V_JORNADAS_DE_EST_DE_SEG.pdf

De Guzman, M. M. (2014). Harsh Justice for International Crimes?. The Yale Journal of International Law, 39(1). Recuperado de https://yalejournalofintllaw. files.wordpress.com/2016/02/39-1-deguzman-harsh-justice-for-international-crimes.pdf

Dondé Matute, J. (2010). El concepto de impunidad: leyes de amnistía y otras formas estudiadas por la Corte Interamericana de Derechos Humanos. En K. Ambos, E. Malarino, \& G. Elsner (Eds.). Sistema Interamericano de Protección de los Derechos Humanos y Derecho Penal Internacional. Tomo I (pp. 263-294). Montevideo: Fundación Konrad-Adenauer. Recuperado de http://www.kas. de/wf/doc/kas_23685-1522-4-30.pdf?121011221909

Forcada Barona, I. (2011). Derecho internacional y justicia transicional. Cuando el Derecho se convierte en religión. Navarra: Aranzadi. 
Hayner, P. B. (2014). Verdades silenciadas. La Justicia transicional y el reto de las Comisiones de la Verdad. Barcelona: Bellaterra.

Méndez, J.E. (2013). Justicia de transición. En R. Escudero Alday, \& C. Pérez González (Eds.), Desapariciones forzadas, represión política y crímenes del franquismo. Madrid: Trotta.

Moreno Ocampo, L. (2007). Transitional Justice in Ongoing Conflicts. En International Journal of Transitional Justice,1(1), 8-9.

Odio Benito, E. (1998). Justice for Peace: No to Impunity. En C. C. Joyner (Ed.), Reining in Impunity for International Crimes and Serious Violations of Fundamental Human Rights: Proceeding of the Siracusa Conference 17-21 September 1998,. Burdeos: Association Internationale de Droit Pénal y Érès.

Odio Benito, E. (2009). Posibles aportaciones del Estatuto de Roma a los procesos judiciales en las sociedades en transición. En J. Almqvist, \& C. Espósito (Coords.), Justicia transicional en Iberoamérica (pp. 241-254). Madrid: Centro de Estudios Políticos y Constitucionales.

Olasolo, H. (2013). El impacto del examen preliminar de la CPI sobre los delitos de LESA humanidad cometidos en Colombia desde el 1 de noviembre de 2002 en el proceso de negociación de paz entre el gobierno y las FARC. En C. M. Díaz Barrado, C. R. Fernández Liesa, \& J. L. Rodríguez-Villasante y Prieto (Dirs.), Derecho Internacional Humanitario y Derechos Humanos: Reflexiones sobre el Conflicto Colombiano. Navarra: Aranzadi.

Olasolo, H. (2014). Los exámenes preliminares de la Corte Penal Internacional en América Latina: el caso colombiano y su impacto sobre futuras negociaciones de paz en la región. Anuario de Derechos Humanos, 10, 35-56.

Orentlicher, D. F. (2007). "Settling Accounts Revisited: Reconciling Global Norms with Local Agency”. International Journal of Transitional Justice, 1(1), 10-22.

Pigrau Solé, A. (2013). Colombia: la investigación pendiente de la Corte Penal Internacional. En C. M. Díaz Barrado, C. R. Fernández Liesa, \& J. L. Rodríguez-Villasante y Prieto (Dirs.). Derecho Internacional Humanitario y Derechos Humanos: Reflexiones sobre el Conflicto Colombiano, (pp. 655-690). Navarra: Aranzadi.

Roht-Arriaza, N. (2015). “After Amnesties are Gone: Latin American National Courts and the new Contours of the Fight Against Impunity". Human Rights Quarterly, 37(2), 341-382. 
Schabas, W. A. (2011). An Introduction to the International Criminal Court. United Kingdom: Cambridge University Press.

Seils, P. (2015). La cuadratura del círculo en Colombia. Los objetivos del castigo y la búsqueda de la paz. ICTJ análisis. Recuperado de https://www.ictj.org/sites/ default/files/ICTJ-COL-Analisis-Penas-ES-2015.pdf

Vacas Fernández, F. (2013). Los derechos de las víctimas y la negociación: el caso de Colombia. En C. M. Díaz Barrado, C. R. Fernández Liesa,\& J. L. Rodríguez-Villasante y Prieto (Dirs.), Derecho Internacional Humanitario y Derechos Humanos: Reflexiones sobre el Conflicto Colombiano, (pp. 541-576). Navarra: Aranzadi.

\section{Documentación Internacional}

African Commission on Human and Peoples' Rights. 87 Resolution on Ending Impunity in Africa and on the Domestication and Implementation of the Rome Statute of the International Criminal Court (5 December 2005).

Amnistía Internacional. (2016). Colombia: El acuerdo de paz debe abrir la puerta a la justicia. Recuperado de https://www.amnesty.org/es/latest/news/2016/12/ colombia-peace-agreement-must-open-the-door-to-justice/

Amnistía Internacional. (2016). Informe 2015/2016 Amnistía Internacional. La situación de los derechos humanos en el mundo. Recuperado de https:// www.amnesty.org/en/documents/pol10/2552/2016/es/

Asamblea General de las Naciones Unidas. Informe del Relator Especial sobre la promoción de la verdad, la justicia, la reparación y las garantías de no repetición. Documento de las Naciones Unidas: A/68/345, de 23 de agosto de 2013.

Asamblea General de las Naciones Unidas. Principios y directrices básicos sobre el derecho de las víctimas de violaciones manifiestas de las normas internacionales de derechos humanos y de violaciones graves del derecho internacional humanitario a interponer recursos y obtener reparaciones. Documento de las Naciones Unidas: A/RES/60/147, de 16 de diciembre de 2005.

Centro de Estudios Sobre Impunidad y Justicia, CESIJ. (2015). Índice Global de Impunidad: IGI 2015. Fundación Universidad de las Américas Puebla. 
Comisión de Derechos Humanos de las Naciones Unidas. Conjunto de principios actualizado para la protección y la promoción de los derechos humanos mediante la lucha contra la impunidad. Documento de las Naciones Unidas: E/CN.4/2005/102/Add.1, de 8 de febrero de 2005.

Comisión de Derechos Humanos de las Naciones Unidas. Estudio independiente, con inclusión de recomendaciones, sobre las mejores prácticas, para ayudar a los estados a reforzar su capacidad nacional con miras a combatir todos los aspectos de la impunidad. Documento de las Naciones Unidas: E/ CN.4./2004/88, de 27 de febrero de 2004.

Comisión de Derechos Humanos de las Naciones Unidas. Impunidad. Documento de las Naciones Unidas: E/CN.4/RES/2005/81, de 21 de abril de 2005.

Comisión de Derechos Humanos de las Naciones Unidas. Informe de Diane Orentlicher, Experta independiente encargada de actualizar el Conjunto de principios para la lucha contra la impunidad. Documento de las Naciones Unidas: E/CN.4/2005/102., de 18 de febrero de 2005.

Comisión de Derechos Humanos de las Naciones Unidas. La administración de justicia y los derechos humanos de los detenidos. Documento de las Naciones Unidas: E/CN.4./Sub.2/1997/20/Rev.1, de 2 de octubre de 1997.

Comisión de Derecho Internacional. Informe de la Comisión de Derecho Internacional, $68^{\circ}$ período de sesiones ( 2 de mayo a 10 de junio y 4 de julio a 12 de agosto de 2016). Documento de las Naciones Unidas: A/71/10.

Comisión Interamericana de Derechos Humanos. Informe Anual 2014, Capítulo V: Seguimiento de recomendaciones formuladas por la CIDH en sus informes de país o temáticos, Seguimiento de recomendaciones formuladas por la CIDH en el Informe Verdad, Justicia y Reparación: Cuarto informe sobre la situación de derechos humanos en Colombia, de 7 de mayo de 2015.

Comisión Interamericana de Derechos Humanos. Informe Anual 2015, Capítulo V: Seguimiento de recomendaciones formuladas por la CIDH en sus informes de país o temáticos, Seguimiento de recomendaciones formuladas por la CIDH en el Informe Verdad, Justicia y Reparación: Cuarto informe sobre la situación de derechos humanos en Colombia, de 17 de marzo de 2016.

Comisión Interamericana de Derechos Humanos. Pronunciamiento de la Comisión Interamericana de Derechos Humanos sobre la aplicación y el alcance de la Ley de Justicia y Paz en la República de Colombia, 2006. 
Comisión Interamericana de Derechos Humanos. Verdad, justicia y reparación: Cuarto informe sobre la situación de derechos humanos en Colombia, OEA/Ser.L/V/II. Doc.49/13, de 31 de diciembre de 2013.

Consejo de Derechos Humanos de las Naciones Unidas. Informe de la Alta Comisionada de las Naciones Unidas para los Derechos Humanos sobre los derechos humanos y la justicia de transición. Documento de las Naciones Unidas: A/HRC/18/23, de 4 de julio de 2011.

Consejo de Derechos Humanos de las Naciones Unidas. Informe del Relator Especial sobre la promoción de la verdad, la justicia, la reparación y las garantías de no repetición, Pablo de Greiff. Documento de las Naciones Unidas: A/ HRC/21/46, de 9 de agosto de 2012.

Consejo de Derechos Humanos de las Naciones Unidas. Informe del Relator Especial sobre la promoción de la verdad, la justicia, la reparación y las garantías de no repetición, Pablo de Greiff. Documento de las Naciones Unidas: A/ $\mathrm{HRC} / 27 / 56$, de 27 de agosto de 2014.

Consejo de Derechos Humanos de las Naciones Unidas. Relator Especial sobre la promoción de la verdad, la justicia, la reparación y las garantías de no repetición. Documento de las Naciones Unidas: A/HRC/RES/18/7, de 13 de octubre de 2011.

Consejo de Derechos Humanos de las Naciones Unidas. Resolución aprobada por el Consejo de Derechos Humanos: Derechos humanos y justicia de transición. Documento de las Naciones Unidas: A/HRC/RES/21/15, de 11 de octubre de 2012.

Consejo de Seguridad de las Naciones Unidas. Resolución aprobada por el Consejo de Seguridad en su 7609a sesión, celebrada el 25 de enero de 2016. Documento de las Naciones Unidas: S/RES/2261, de 25 de enero de 2016.

Corte Penal Internacional. Carta de la Fiscal de la CPI al Presidente de la Corte Constitucional acerca del Marco Jurídico para la Paz, de 26 de julio de 2013. Recuperado de http://www.derechos.org/nizkor/colombia/doc/cpicol7.html

Corte Penal Internacional. Declaración de la Fiscal sobre el Acuerdo de creación de una Jurisdicción Especial para la Paz en Colombia, de 24 de septiembre de 2015. Recuperado de https://www.icc-cpi.int//Pages/item.aspx?name=otp_stat_24-09-2015\&ln=Spanish 
Corte Penal Internacional. Documento de política general sobre exámenes preliminares, Noviembre de 2013 (ICC - OPT 2013).

Corte Penal Internacional. Informe sobre las Actividades de Examen Preliminar de 2014 (Situaciones en Honduras y Colombia), 2 de diciembre de 2014.

Corte Penal Internacional. Informe sobre las Actividades de Examen Preliminar (2015): Situaciones en Colombia y Honduras, 12 de noviembre de 2015.

Corte Penal Internacional. Informe sobre las actividades de examen preliminar (2016): Situación en Colombia, 14 de noviembre de 2016.

Corte Penal Internacional Situación en Colombia: Reporte Intermedio, Noviembre 2012.

Council of Europe. Eradicating impunity for serious human rights violations, Guidelines adopted by the Committee of Ministers on 30 March 2011 at the $1110^{\text {th }}$ Meeting of the Ministers' Deputies.

Declaración y programa de acción de Viena. Aprobados por la Conferencia Mundial de Derechos Humanos el 25 de junio de 1993.

Human Rights Watch (2015). Análisis de Human Rights Watch sobre el Acuerdo sobre las Víctimas del Conflicto alcanzado por el Gobierno de Colombia y las FARC. Recuperado de https://www.hrw.org/es/news/2015/12/21/analisis-dehuman-rights-watch-sobre-el-acuerdo-sobre-las-victimas-del-conflicto

Human Rights Watch (2015). Colombia: un acuerdo de impunidad. Recuperado de https://www.hrw.org/es/news/2015/12/22/colombia-un-acuerdo-de-impunidad

Human Rights Watch (2016). Carta al Presidente Santos sobre el nuevo acuerdo de paz con las FARC. Recuperado de https://www.hrw.org/es/news/2016/11/23/ carta-al-presidente-santos-sobre-el-nuevo-acuerdo-de-paz-con-las-farc

Oficina del Alto Comisionado de las Naciones Unidas para los Derechos Humanos. Instrumentos del Estado de derecho para sociedades que han salido de un conflicto: Comisiones de la verdad, HR/PUB/06/1.

Oficina del Alto Comisionado de las Naciones Unidas para los Derechos Humanos. Instrumentos del Estado de derecho para sociedades que han salido de un conflicto: Iniciativas de enjuiciamiento, HR/PUB/06/4. 
Oficina del Alto Comisionado de las Naciones Unidas para los Derechos Humanos. Instrumentos del Estado de derecho para sociedades que han salido de un conflicto: Procesos de depuración: marco operacional, HR/PUB/06/5.

Oficina del Alto Comisionado de las Naciones Unidas para los Derechos Humanos. Instrumentos del Estado de derecho para sociedades que han salido de un conflicto: Programa de reparaciones, $\mathrm{HR} / \mathrm{PUB} / 08 / 1$.

Oficina del Alto Comisionado de las Naciones Unidas para los Derechos Humanos. Instrumentos del Estado de derecho para sociedades que han salido de un conflicto: Amnistías, HR/PUB/09/1.

Oficina del Alto Comisionado de las Naciones Unidas para los Derechos Humanos. Consultas nacionales sobre la justicia de transición, HR/PUB/09/2.

Oficina del Alto Comisionado de las Naciones Unidas para los Derechos Humanos. Justicia transicional y derechos económicos, sociales y culturales, H/ $\mathrm{PUB} / 13 / 5$.

Secretario General de las Naciones Unidas. El Estado de derecho y la justicia de transición en las sociedades que sufren o han sufrido conflictos. Documento de las Naciones Unidas: S/2004/616, de 3 de agosto de 2004.

Secretario General de las Naciones Unidas. El estado de derecho y la justicia de transición en las sociedades que sufren o han sufrido conflictos. Documento de las Naciones Unidas: S/2011/634, de 12 de octubre de 2011.

\section{Colombia}

Acuerdo Final para la Terminación del Conflicto y la Construcción de una Paz Estable y Duradera, del 12 de noviembre de 2016.

Acuerdo sobre las Víctimas del Conflicto, Borrador Conjunto de 15 de diciembre de 2015: "Sistema Integral de Verdad, Justicia, Reparación y No Repetición", incluyendo la Jurisdicción Especial para la Paz; y Compromiso sobre Derechos Humanos.

Carta de Alejandro Ordoñez Maldonado, Procurador General de la Nación, a la Sña. Fatou Bensouda, Fiscal Jefe de la Corte Penal Internacional, Bogotá, a 19 de enero de 2016. Recuperado de http://www.procuraduria.gov.co/ portal/media/file/portal_doc_interes//216_190116COMUNICACION.pdf

Comunicado conjunto de 7 de junio de 2014, La Habana: "Declaración de principios para la discusión del Punto 5 de la Agenda: "Víctimas". 
Comunicado Conjunto No. 4, La Habana, Cuba, 12 de noviembre de 2016.

Comunicado Conjunto No. 60 sobre el Acuerdo de creación de una Jurisdicción Especial para la Paz, La Habana, Cubra, 23 de septiembre de 2015.

\section{Jurisprudencia}

Corte Penal Internacional

CPI [SPI I]. The Prosecutor v Thomas Lubanga Dyilo. Decision on Sentence pursuant to article 76 of the Statute. ICC-01/04-01/06-2901. 10 de Julio de 2012.

CPI [SPI II]. The Prosecutor v Germain Katanga. Decision on Sentence Pursuant to article 76 of the Statute. Sala de Primera Instancia II. ICC-01/04-01/073484. 23 de mayo de 2014.

CPI [SPI III]. The Prosecutor v Jean Pierre Bemba Gombo. Decision on Sentence Pursuan to Article 76 of the Statute. ICC-01/05-01/08-3399. 21 de Junio de 2016.

CPI [SPI VIII]. The Prosecutor v Ahmad Al Faqui Al Mahdi. Judgemt and Sentence. ICC-01/12-01/15. 27 de Septiembre de 2016.

Tribunal Internacional para la ex Yugoslavia

TIPY [SPI].The Prosecutor v. Drazen Erdemovic. Sentencing Judgement. IT-9622-T. 29 de Noviembre de 1996.

Corte Interamericana de Derechos HumanosCorte IDH. "Panel Blanca" (Paniagua Morales y otros) c. Guatemala. Decisión de Fondo. 8 de marzo de 1998. Serie C No. 37.

Corte IDH. Masacre de La Rochela c. Colombia. Decisión de Fondo, Reparaciones y Costas. 11 de mayo de 2007. Serie C No. 163.

Corte IDH. Heliodoro Portugal c. Panamá. Decisión sobre Excepciones Preliminares, Fondo, Reparaciones y Costas. 12 de agosto de 2008. Serie C No. 186.

Corte IDH. Manuel Cepeda Vargas c. Colombia. Decisión de Excepciones Preliminares, Fondo, Reparaciones y Costas. 26 de mayo de 2010. Serie C No. 213.

Corte IDH. Masacres de El Mozote y lugares aledaños c. El Salvador. Decisión de Fondo, Reparaciones y Costas. 25 de octubre de 2012. Serie C No. 252. 
Corte IDH. Masacres de El Mozote y lugares aledaños c. El Salvador. Voto concurrente del Magistrado Diego García - Sayán a la Decisión de Fondo. Reparaciones y Costas. 25 de octubre de 2012. Serie C No. 252.

Corte IDH. Comunidades Afrodescendientes Desplazadas de la Cuenca del Río Cacarica (Operación Génesis) c. Colombia. Decisión sobre Excepciones Preliminares, Fondo, Reparaciones y Costas. Sentencia de 20 de noviembre de 2013. Serie C No. 270.

Corte IDH. Rodríguez Vera y otros (Desaparecidos del Palacio de Justicia) c. Colombia. Decisión de Excepciones Preliminares, Fondo, Reparaciones y Costas. 14 de noviembre de 2014. Serie C No. 287.

\section{Conferencias}

James Stewart, Fiscal Adjunto de la Corte Penal Internacional: "La justicia transicional en Colombia y el papel de la Corte Penal Internacional”. Conferencia organizada por La Universidad del Rosario, El Tiempo, el Centro Cyrus $\mathrm{R}$ Vance para las Iniciativas de Justicia Internacional, la Fundación Hanns Seidel, las Naciones Unidas en Colombia, el Centro Internacional para la Justicia Transicional y la Coalición por la Corte Penal Internacional, Bogotá, Colombia, 13 de mayo de 2015. Recuperado de https://www.icc-cpi.int/ iccdocs/otp/otp-stat-13-05-2015-SPA.pdf

Schabas, W.A. (2011). Transitional Justice and the Norms of International Law. For presentation to the Annual meeting of the Japanese Society of International Law, Kwansei Gakuin University, 8 October 2011. Recuperado de http://jsil. jp/annual_documents/2011/fall/schabas_trans_just911.pdf

\section{Prensa}

Ambos, K. (26 de septiembre de 2015). “¡Tanta justicia sí permite la paz!”. En El Espectador. Recuperado de http://www.elespectador.com/opinion/tanta-justicia-si-permite-paz

"El acuerdo cumple con criterios de Fiscal de la CPI" (27 de septiembre de 2015). En El Tiempo. Recuperado de http://www.eltiempo.com/politica/proceso-de-paz/proceso-de-paz-el-acuerdo-cumple-con-criterios-de-fiscal-de-lacpi/16388808 
"El proceso de paz de Colombia es ejemplar": experta en justicia transicional (10 de febrero de 2016). En El País.com.co. Recuperado de http://www. elpais.com.co/elpais/colombia/proceso-paz/noticias/proceso-paz-colombia-ejemplar-experta-justicia-transicional

"No era necesario someter el acuerdo de paz al voto popular" (18 de noviembre de 2016). En Semana. Recuperado de http://www.semana.com/nacion/articulo/kai-ambos-habla-sobre-el-acuerdo-de-paz-y-el-plebiscito/505809

Uprimny, R. (26 de septiembre de 2015). “Justicia imperfecta, paz posible”. En El Espectador. Recuperado de http://www.elespectador.com/opinion/justicia-imperfecta-paz-posible

Uprimny, R. (26 de diciembre de 2015). “¿Piñata de impunidad?”. En El Espectador. Recuperado de http://www.elespectador.com/opinion/pinata-de-impunidad Uprimny, R. (19 de noviembre de 2016). “Un acuerdo sobre el acuerdo”. En El Espectador. Recuperado de http://www.elespectador.com/opinion/un-acuerdo-sobre-el-acuerdo 